\title{
Impacts of sparing use of water on farmer income of China
}

\author{
Zhan Wang ${ }^{\mathrm{a}, \mathrm{c}}$, Xiangzheng Deng ${ }^{\mathrm{b}, \mathrm{c}, *}$, Jiancheng Chen ${ }^{\mathrm{a}}$ \\ ${ }^{a}$ School of Economics E' Management, Beijing Forestry University, Beijing 100083, China \\ ${ }^{\mathrm{b}}$ Institute of Geographic Sciences and Natural Resources Research, Chinese Academy of Sciences, Beijing 100101, China \\ ${ }^{\mathrm{c}}$ Center for Chinese Agricultural Policy, Chinese Academy of Sciences, Beijing 100101, China
}

\section{A R T I C L E I N F O}

\section{Article history:}

Received 31 January 2015

Received in revised form 31 July 2015

Accepted 20 September 2015

Available online 25 September 2015

\section{Keywords:}

Water use

Farmer

Income

Water saving

China

GMM

\begin{abstract}
A B S T R A C T
We examine relationships between nationwide sparing use of water and farmer income of China in this article. As increasing implementation of water projects and irrigation system, the cost of water use has increased in many regions. However, as local policy-oriented urban expansion and ecological restoration have carried out during the past decade, water demand has increased. The spatial distributions of water use and farmer income are uneven and their relationships are ambiguous over time, especially it is uncertain that farmers can benefit from those so called water-saving programs when urban expansion grows faster in China. Based on consumption theory, empirical results of Blundell-Bond dynamic panel-data model with generalized method of moments (GMM) estimators indicate saving one percent of water has positive impacts at $0.085-0.35$ percent on farmer income in the following statistical year. Population has negative impacts on farmer income. Particularly in Central China, one percent of increase in population will statistically significantly decrease 0.276 percent of contemporaneous farmer income. Particularly, in Eastern China with large population during years 2004 through 2012, the total amount of water use increases one percent, contemporaneous farmer income loses 0.04 percent. Thus, saving water can benefit future farmer income, and it indicates that urban expansion may induce the diversion of resources and agricultural production from rural to urban area. Policy implication of relationships between water allocation and farmer income distribution caused by water-saving programs needs to be further studied at regional scale, in particularly to the regions with large population and urban expansion in China.
\end{abstract}

(c) 2015 Elsevier Ltd. All rights reserved.

\section{Introduction}

The Word Bank reported that per capita water use is one of key indicators to measure human-wellbeing (Rosegrant et al., 2002). With world-wide increasing demand of economic development with eco-environmental protection (Singh, 1998), water demand of environmental adaptation have been raised up (World Bank Group, 2012) and which is driven by the impacts of both local policy-oriented urban expansion and regional climatic changes (Jiang et al., 2014). China is one of countries severely lack of water (Deng and Zhao, 2014). The per-capita water resource in China is less than 2100 cubic meter, only 28 percent of the world average until 2000s. China, thereby, aims to set an ideal "water-saving society", and have broadly implemented water-saving techniques in both urban and rural area (Deng et al., 2014). There are four categories of synchronous implementation for water-saving

* Corresponding author at: Institute of Geographic Sciences and Natural Resources Research, Chinese Academy of Sciences, Beijing 100101, China.

E-mail addresses: lizwang128@gmail.com (Z. Wang), dengxz.ccap@gmail.com (X. Deng), chenjc1963@163.com (J. Chen). techniques in agricultural production, industrial processing, residential living, and municipal construction (National Agricultural Water-Saving Outlines For 2012-2020, 2012). However, when facing water shortage at regional scale (Kelly, 2014), heterogeneity may counteract benefits of water-saving implementation at national scale. Particularly, in terms of Wang et al. (2002) studied that agricultural use of water accounts for over 70 percent of the total amount of water in China until 2000s, there are still lack of researches studying how the real farmer income has been influenced by water use changes over time.

According to National Agricultural Water-Saving Outlines For 2012-2020 published by The Ministry of Water Resource of the P.R. China in year 2012, water-saving programs efficiently retarded the consumption of water stock. Water use efficiency had increased about 20 percent from year 2000 to 2013. Especially, irrigated water use per ha decreased from 15 cubic meter in year 2000 to 24 cubic meter in year 2013. However, with the increasing demand of water in urban area, water use proportional changes of agricultural sectors and non-agricultural sectors fluctuated under three percent over time, and the growth rate of the total amount of water use was continually increasing about one percent 
per year (see Fig. 1). Therefore, we do not know yet whether farmers will benefit from the national water-saving programs when China's urban expansion grows faster.

Water-saving programs pushed relevant industrial transformation. Through the advanced drought-enduring seeds were fostered and wide sowed, per cubic meter water input on average yield of crops had arisen from $1.33 \mathrm{~kg}$ in year 2000 to $1.75 \mathrm{~kg}$ in year 2013 . The efficiency of fertilizer and pesticide use with respect to yield was improved around 15 percent. Over 2000 firms had invested on research and development of water-saving technique and equipment, which successfully supported annual increase of irrigation facilities covering over 200 million ha per year. Until year 2013, irrigated area were 63.47 million ha, about 43 percent of them covered by irrigation facilities. Moreover, in terms of regulations of regional water quota, implementation of forced water-saving technique, and installation of water-saving equipment for industrial water consumption and retreatment, all of that with some state subsidies had positive impacts on the relevant industries to some extant saving cost of water consumption (Deng et al., 2014).

Impacts of sparing use of water on farmer income of China are rarely researched. Blanke et al. (2007) tended to study household behaviors to irrigated water-saving against drought resistant of cultivation, and discussed water-saving technology development and its acceptance in China. Gilg and Barr (2006) did survey research to find evidence that motivation of household behaviors for water-saving through the purchase investment decision of water-saving facilities and their water use actions. These ideational research designs probe into perception of respondents on watersaving facilities that were practically used in daily living or agricultural production. Wang et al. (2015) analyzed economic welfare of rural and urban residents can benefit from water projects at regional scale that supposed to be achieved by either regional or national government investments to irrigation facilities. However, we do not know yet how much farmer income benefit from sparing use of water at the national level.

In the rest of this article, we review the status of water use in China in the following section, and briefly point out uneven spatial distribution and fuzzy relationships among water use, population, and farmer income of Eastern China, Central China, and Western China. In third section, the empirical models are built up based on a sequential series of hypotheses, and data description are introduced for technical clarification and professional verification. The empirical results and our analysis are given in the fourth section to clarify the fuzzy relationships and verify our hypotheses. The final section presents the conclusions and policy implications.

\section{Background}

Spatial distribution of the total amount of water use is uneven in China. According to regional division of China in geographical categories, there were three large regions: Eastern China, Central China, and Western China. In year 2012, there were 556 billion ton water used in China. Eastern China consumed 218 billion ton of water, accounts for 40 percent of the total amount of water use in year 2012. In Eastern China, Jiangsu (55 bt), Guangdong (45 bt), and Shandong ( $22 \mathrm{bt}$ ) were the top-three highest provinces in water use, as shown in Table 1. Central China used 196 billion ton of water in year 2012. Heilongjiang (36 bt), Hunan (33 bt), and Hubei (29 bt) were the top-three highest provinces in water use. Western China spent 141 billion ton of water, and Guangxi (30 bt), Sichuan (24 bt), and Inner Mongolia (18 bt) were the top-three highest provinces in water use.

Spatial distribution of per capita water use is uneven in China. The per capita water use is the amount of total water use per person, which is the total amount of water use in year 2012 divided by the total population of each province in China. Popula-
Table 1

Total amount of water use in each province of China in year 2012.

\begin{tabular}{|c|c|c|c|c|c|}
\hline \multicolumn{2}{|c|}{ Eastern China } & \multicolumn{2}{|l|}{ Central China } & \multicolumn{2}{|c|}{ Western China } \\
\hline Beijing & 3588 & Shanxi & 7339 & $\begin{array}{l}\text { Inner } \\
\text { Mongolia }\end{array}$ & 18,435 \\
\hline Tianjing & 2313 & Jilin & 12,982 & Guangxi & 30,301 \\
\hline Hebei & 19,531 & Heilongjiang & 35,890 & Chongqing & 8294 \\
\hline Liaoning & 14,223 & Anhui & 29,264 & Sichuan & 24,592 \\
\hline Shanghai & 11,598 & Jiangxi & 24,254 & Guizhou & 10,082 \\
\hline Jiangsu & 55,223 & Henan & 23,861 & Yunnan & 15,183 \\
\hline Zhejiang & 19,812 & Hubei & 29,929 & Tibet & 2981 \\
\hline Fujian & 20,008 & Hunan & 32,880 & Shaanxi & 8804 \\
\hline Shandong & 22,179 & & & Gansu & 12,305 \\
\hline Guangdong & 45,102 & & & Qinghai & 2740 \\
\hline \multirow[t]{2}{*}{ Hainan } & 4533 & & & Ningxia & 6935 \\
\hline & & & & Xinjiang & 590 \\
\hline Total & 218,110 & & 196,399 & & 141,242 \\
\hline
\end{tabular}

Note: amount of water used is measured in million ton. Data source: NBSC in year 2012.

Table 2

Amount of per capita water use in each province of China in year 2012.

\begin{tabular}{llllll}
\hline Eastern China & & Central China & \multicolumn{3}{c}{ Western China } \\
\hline Beijing & 173.4 & Shanxi & 203.2 & Inner Mongolia & 740.4 \\
Tianjing & 163.7 & Jilin & 472.1 & Guangxi & 647.2 \\
Hebei & 268.0 & Heilongjiang & 936.1 & Chongqing & 281.6 \\
Liaoning & 324.1 & Anhui & 488.7 & Sichuan & 304.5 \\
Shanghai & 487.3 & Jiangxi & 538.5 & Guizhou & 289.4 \\
Jiangsu & 697.3 & Henan & 253.7 & Yunnan & 325.9 \\
Zhejiang & 361.7 & Hubei & 517.9 & Tibet & 967.9 \\
Fujian & 533.8 & Hunan & 495.3 & Shaanxi & 234.6 \\
Shandong & 229.0 & & & Gansu & 477.3 \\
Guangdong & 425.7 & & & Qinghai & 478.2 \\
Hainan & 511.1 & & & Ningxia & 1071.9 \\
& & & & Xinjiang & 26.4 \\
Average & 390.5 & & 462.0 & & 387.7 \\
\hline
\end{tabular}

Note: Amount of per capita water use is measured in ton. Data source: NBSC in year 2012.

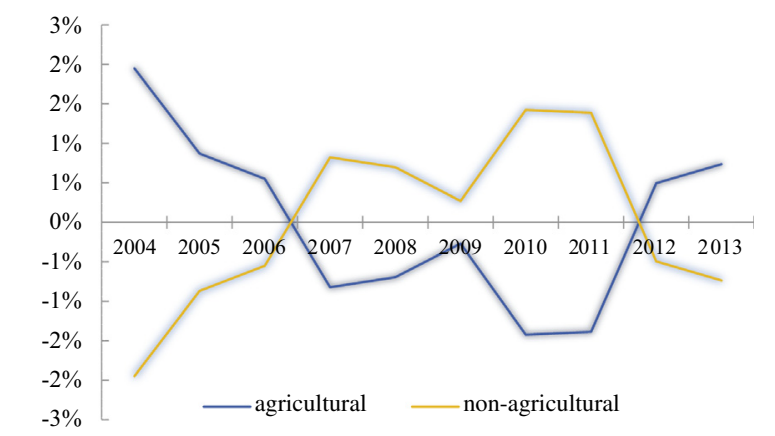

Data source: National Bureau of Statistics of China (NBSC) in years 2004-2013.

Fig. 1. Water use proportional changes of agricultural sectors and non-agricultural sectors in the years 2004 through 2012.

tion of China was up to 1347.89 million by the end of year 2012. As Table 2 shows, the highest average of per capita water use was in Central China (462 t). That of in Eastern China (390 t) and Western China $(388 \mathrm{t}$ ) were quite close in year 2012. Per capita water use of Shanxi (203 t), Henan (254 t), and Jilin (472 t) were the three lowest in Central China; Tianjing (164t), Beijing (173 t), and Shandong $(229 \mathrm{t})$ were the three lowest in Eastern China; and Xinjiang (26 t), Shannxi $(235 \mathrm{t})$, and Chongqing (282 t) were the three lowest in Western China in year 2012.

The relationship between water use and farmer income is ambiguous. According to the statistics of NBSC year 2004-2013, 
Table 3

Average farmer income in each province of China in 2012 USD.

\begin{tabular}{llllll}
\hline Eastern China & & Central China & \multicolumn{3}{l}{ Western China } \\
\hline Beijing & 2610.0 & Shanxi & 1007.0 & Inner Mongolia & 1205.8 \\
Tianjing & 2221.9 & Jilin & 1362.1 & Guangxi & 951.7 \\
Hebei & 1280.2 & Heilongjiang & 1363.0 & Chongqing & 1169.6 \\
Liaoning & 1486.5 & Anhui & 1134.3 & Sichuan & 1109.1 \\
Shanghai & 2820.4 & Jiangxi & 1240.3 & Guizhou & 753.0 \\
Jiangsu & 1933.0 & Henan & 1192.1 & Yunnan & 858.1 \\
Zhejiang & 2305.3 & Hubei & 1243.8 & Tibet & 906.0 \\
Fujian & 1579.0 & Hunan & 1178.6 & Shaanxi & 912.9 \\
Shandong & 1496.5 & & & Gansu & 713.9 \\
Guangdong & 1670.1 & & & Qinghai & 849.8 \\
Hainan & 1173.5 & & & Ningxia & 979.1 \\
& & & & Xinjiang & 1012.9 \\
Average & 1870.6 & & 1215.2 & & 951.8 \\
\hline
\end{tabular}

Data source: NBSC in year 2012.

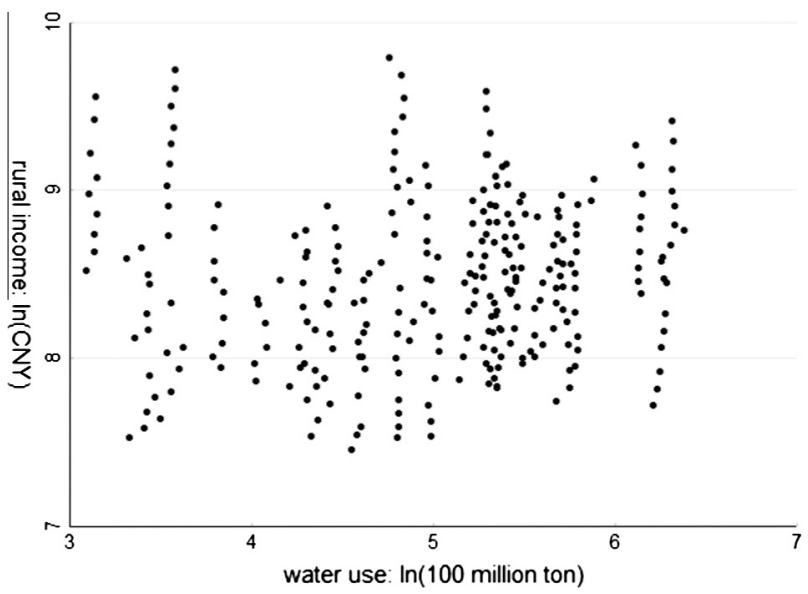

Fig. 2. Scatter plot of unobserved relationships between water use and farmer income in China in Napierian logarithmic numbers for the years 2004 through 2012.

the average of farmer income in each province of Eastern China was about 1871 in 2012 USD, which was the highest among three large regions, and that of Central and Western China were sequentially about 1215 and 952 in 2012 USD as shown in Table 3. Obviously, Eastern China has the highest water use and the highest average of farmer income. It seems that there is a linear positive relationship between the total amount of annual water use and the average of contemporaneous farmer income during years 2004-2012. However, this relationship is uncertain with population distribution and may vary over time, as Fig. 2 shows that their scatter plot does not show any observable relationship from year 2002 to 2012.

\section{Empirical model}

\subsection{Key variables}

Farmer income is mainly from selling agricultural production. Water usually is considered as a kind of special goods either as common-pool goods with low price or as free public goods attribute to water rights in an agricultural production process (Perry et al., 1997). Classic economic theory addresses that total consumption demand drives the market equilibrium points back to the optimum path (Samuelson, 1948). Under the assumption of unlimited natural resource with unlimited technology improvements, higher demand of resources consumption kicks the critical point at the higher price, and driving the bigger gap between demand and supply so that lead to market failures when faces limited resource supply in reality. Water is a kind of special goods, which carries the capacity of both goods and bads. The more water intake, the more discharge with pollution are generated over spatial-temporal distribution. Kelman (1978) reinforced an ideology in Coase theorem by introducing a case study of externality of upstream water pollution in a maximum production process influencing to downstream residential water consumption and bringing about potential agricultural loss of environmental deterioration. This unpredictable losses are caused by overconsumption and disordered exploration of natural resource in the transaction process of economic development with consumption demand increases. Furthermore, it is quite difficult to evaluate social welfare benefited from industrial transformation but lose from environmental deterioration in the past two centuries, although residential quality of life in some regions has been improved (Wade, 1990). However, that overuse of water and exploration of other resource is still a hard-core strategy for world development (Solow, 1974). Indeed, China's water shortage has been harming farmer income and threatening worldwide agricultural production due to huge demand of food security (Brown and Halweil, 1998). Therefore, the debates between theoretical detection and empirical study have arisen to discuss utilization of water resource in sustainability.

In this research, we aim to study farmer income (ln finc) changes caused by water consumption, and seek the impact of sparing water use (ln water) on farmer income changes. We started from a Pool-OLS regression as the following Eq. (1) shows, which will give a brief picture of the relationships between dependent and independent variables. See the derivation steps in Appendix A.1

In finc $=\alpha+\beta_{1} \ln$ pop $+\beta_{2} \ln w a t e r+\beta_{3} \ln$ ele $+e$

where $\beta_{1}$ is the elasticity of how many percent changes in farmer income (ln finc) in one percent changes in population (ln pop); $\beta_{2}$ presents how many percent changes in farmer income (ln finc) in one percent changes in water use (ln water) changes; and $\beta_{3}$ is the elasticity of how many percent changes in farmer income (ln finc) in one percent changes in electric power (ln ele). $\alpha$ is the unknown intercept, and $e$ is the error term.

Viewed from the macro perspective on water allocation, electric power usually is used for representing the capability of water achievement in a region (Cabraal et al., 2005), which is assumed economic assessment of a level of regional development inclines to the level of electric power consumption, and presents the difference of regional characteristics of regional economies in China. For this reason, we set a Fixed Effect model to further look over both structural changes and variation changes at the provincial level from year 2004 to 2012 in the following constructed Eq. (2).

$$
\begin{aligned}
\ln \text { finc }_{i t}= & \alpha_{i t}+\beta_{1} \ln \text { pop }_{i t}+\beta_{2} \ln \text { water }_{i t}+\beta_{3} \ln \text { ele }_{i t}+\mu_{i} \\
& +\epsilon_{i t}
\end{aligned}
$$

where, $\mu_{i}$ catches the individual-level effect in each region $i=1$, $2, \ldots, 31$ in China, and $\epsilon_{i t}$ captures the cross-sectional effect of panels over variant time $t=$ year $2004,2005, \ldots, 2012$.

To examine temporal impacts of regional characteristics of independent variables on farmer income, all variables in a panel dataset have to be tested in a stationary series (Maddala and $\mathrm{Wu}$, 1999). Intuitively, economic indices including farmer income, population and electric power consumption would be in a stationary increasing trend. While water use depends on the fluctuated supply of natural resource over time, it may not be in stationary. If the unit-root test for panel data models prove the above assumptions by using STATA software, the results reported by Fixed Effect model may distort temporal impacts of water use on farmer income. In order to stick out those defects, a dynamic panel-data model would be considered to suit for this issue. In other words, the results of Fixed Effect model will prove the 
impacts of water use changes on farmer income cannot be ignored even if this model not suitable for this case study.

\subsection{Identification of autocorrelation}

Water use at national level is supposed as one of key exogenous variables to farmer income. On the one hand, every increase of water use for agricultural production is assumed to have linear relationships with every increase of yield of crops, so that how much the increasing demand of production are depending on increasing water demand in all productive processes. Hence, we assume the water use for non-agricultural sectors affecting the changes in total amount of water use for agricultural, but the competition between water use for agricultural and non-agricultural them is exogenous to farmer income. It means the total amount of water use at national level is an exogenous variables to farmer income.

On the other hand, human activities on innovation of techniques have created gigantic changes in nature. Water projects have generated electric hydropower that has been transmitted into innumerable homes and factories, and large water transportation and irrigation facilities have improved living standard (Wang et al., 2015). It to some extent marks civilization on human history. The higher level of civilization with advanced technology, the higher possibility of engineering projects have been operated to generate hydropower. Thereby, the correlation between water use and electric power may induce autocorrelation in stochastic error over time. Linear dynamic panel-data model (DPD) with predetermined farmer income level with first difference dependent variable (Arellano and Bond, 1991) thus can be nested with a generalized method of moments (GMM) estimator to catch the autocorrelation. The following autoregressive Eq. (3) presents the developed model.

$\ln$ finc $_{i t}=\alpha_{i t}+\gamma \ln$ finc $_{i t-1}+\beta_{1} \ln$ pop $_{i t}+\beta_{2} \ln$ water $_{i t}$

$$
+\beta_{3} \ln \text { ele }_{i t}+\mu_{i}+\delta_{i t}+\varepsilon_{i t}
$$

where $\delta_{i t}$ is the possibly autoregressive shock, and $\varepsilon_{i t}$ reflects uncorrelated measurement errors within intercept over temporal variation.

The Sargan test will judge the necessity to further dealing with autocorrelation if the null hypothesis: validation of overidentifying restrictions is rejected (Bowsher, 2002). If the autocorrelation still exist between the unobserved panel-level effects and the lagged dependent variables, specification of GMM instruments for the differenced equation can be identified as two parts of differenced equation and level equation. If the estimation of Arellano-Bond linear dynamic panel-data estimator with GMM instruments are failed in the Arellano-Bond Test which is testing for zero autocorrelation in first-differenced errors and meaning for efficiency of estimation, the Systematic GMM estimation is preferred to be set with first time-lag differencing model as shown in the following Eq. (4):

$$
\begin{aligned}
\Delta \ln \text { finc }_{i t}= & \alpha_{i t}+\gamma \Delta \ln \text { finc }_{i t-1}+\beta_{1} \Delta \ln \text { pop }_{i t} \\
& +\beta_{2} \Delta \ln \text { water }_{i t}+\beta_{3} \Delta \ln \text { ele }_{i t}+\pi_{i}+\epsilon_{i t}+\gamma \epsilon_{i t-1}
\end{aligned}
$$

Blundell and Bond (1998, 2000) enhanced GMM estimators and figured out an alternative estimator at the cost of a more complicated syntax. It aims to clarify the assumed exogenous effects from mixed errors in residuals by allowing additional moment conditions. The arguments are raised by inefficient Sargan test on a large number of instrumental variables as GMM to finite sample. Within few time periods and relative more panels, Blundell \& Bond dynamic panel-data model with GMM estimators of both farmer income and water use thereby fail to reject that "no autocorrelation in the idiosyncratic errors" even if it may let Sargan test to be inefficient and let Arellano-Bond test to be slack. Thus, for the empirical analysis in this research, we have to scarify a little bit efficiency of asymptotic standard errors of the coefficients for sticking out the autocorrelation in residuals to set GMM estimator only of farmer income. Therefore, the Blundell \& Bond dynamic panel-data model with a GMM estimator is assumed to efficiently suit for this study if the null hypothesis of Arellano-Bond test fails to be rejected.

\subsection{Data description}

Data are derived from the (NBSC, year 2004-2012). Specified variables are including dependent variable: farmer income ( $\ln$ finc), and independent variables: Population (ln pop), Water use (ln water), and Electric power (In ele) of thirty-one provinces of China. All variables are transformed into Napierian logarithmic format for estimating relationships in elasticity. See the derivation steps in Appendix A.1. The following Table 4 presents the summary statistics of all the variables of thirty-one provinces of China. The separated data descriptions of three large region are attached in Table 7 of Appendix A.2.

\section{Empirical analysis results}

\subsection{National trend}

The results from Pool-OLS report biased estimation of the increase of water use having negative impacts on farmer income in China. See Table 5. The arguments here that coefficient of water use with a negative sign is not in statistical significance. Then, the fixed-effect model is designed for specifying stability of the regression with regional characteristics of water use for farmer income in each province. Exactly as our assumptions, the estimation results show that water use is one of the key elements to farmer income. Comparing to individual effect, within-panel serial correlation in the idiosyncratic error term is much lower. It indicates heterogeneity in fixed-effect model inclines to regional identification with less heteroskedasticity, so that the regional characteristics are significantly distinguished (Table 5). However, the Unit-Root test with Fisher Option of either Dickey-Fuller test or Phillips-Perron test proves our previous assumptions that the Fix Effect model may distort stochastic error tem in temporal variation because all test results fail to reject the null hypothesis that unit-root exits in the variables of Farmer income, Population, Electric Power, but not in Water use.

To further study variation of impacts over time, and to identify the possibility of distortion due to autocorrelation, the dynamic panel-data model with systematic GMM (DPD-SYS) is introduced to specify time lags caused by autocorrelation in error term. Empirical results of DPD-SYS show that population size in China is statis-

\section{Table 4}

Data description of specified variables of thirty-one provinces of China during years 2004-2012.

\begin{tabular}{lllllll}
\hline Variable & & Mean & Std. dev. & Min & Max & Observations \\
\hline Farmer income & Overall & 8.41 & 0.56 & 7.29 & 9.88 & $N=372$ \\
[ln finc] & Between & 0.37 & & 7.88 & 9.29 & $n=31$ \\
& Within & 0.42 & & 7.68 & 9.19 & $T=12$ \\
Population & Overall & 8.06 & 0.87 & 5.55 & 9.27 & $N=434$ \\
[ln pop] & Between & 0.88 & & 5.65 & 9.17 & $n=31$ \\
& Within & 0.05 & & 7.84 & 8.31 & $T=14$ \\
Water use & Overall & 4.94 & 0.84 & 3.09 & 6.38 & $N=279$ \\
[ln water] & Between & 0.85 & & 3.13 & 6.30 & $n=31$ \\
& Within & 0.06 & & 4.73 & 5.14 & $T=9$ \\
Electric power & Overall & 6.18 & \multirow{2}{*}{1.00} & 2.56 & 8.44 & $N=603$ \\
[ln ele $]$ & Between & 0.91 & & 2.92 & 7.44 & $n=31$ \\
& Within & 0.63 & & 4.63 & 7.66 & $T=19$
\end{tabular}

Note: $N$ is the observations in $n$ provinces of $T$ time periods. Data within the missing years did not participate analysis. 
Table 5

Estimation results on the impact of water use on farmer income at provincial level of China during years 2004-2012.

\begin{tabular}{|c|c|c|c|c|c|}
\hline Variables & Pool-OLS & $\begin{array}{l}\text { Fixed } \\
\text { effect }\end{array}$ & $\begin{array}{l}\text { DPD-SYS } \\
\text { robust }\end{array}$ & $\begin{array}{l}\text { Blundell- } \\
\text { Bond } \\
\text { robust } \\
\text { DPD }\end{array}$ & $\begin{array}{l}\text { BB robust } \\
\text { DPD GMM } \\
\text { of lag farmer } \\
\text { income }\end{array}$ \\
\hline $\begin{array}{l}\text { Population } \\
\text { [ln pop] }\end{array}$ & $\begin{array}{l}-0.356 \\
(.0587)^{* * * *}\end{array}$ & $\begin{array}{l}0.776 \\
(.1578)^{* * * *}\end{array}$ & $\begin{array}{l}-0.150 \\
(.0237)^{* * * *}\end{array}$ & $\begin{array}{l}-0.355 \\
(.2688)\end{array}$ & $\begin{array}{l}-1.479 \\
(.5919)^{* *}\end{array}$ \\
\hline Water use & -0.027 & 0.641 & 0.077 & 0.118 & 0.190 \\
\hline [ln water] & $(.0436)$ & $(.1028)^{* * *}$ & $(.0222)^{* * *}$ & $(.0495)^{* *}$ & $(.1108)^{* *}$ \\
\hline $\begin{array}{l}\text { Electric } \\
\text { power }\end{array}$ & 0.484 & 1.000 & 0.096 & 0.259 & 0.415 \\
\hline [ln ele] & $(.0411)^{* * * *}$ & $(.0246)^{* * * *}$ & $(.0152)^{* * * *}$ & $(.0710)^{* * *}$ & $(.1145)^{* * *}$ \\
\hline Intercept & 8.234 & -7.698 & 0.5819 & 0.280 & 4.703 \\
\hline [_cons] & $(.2373)^{* * * *}$ & $(1.3483)^{* * * *}$ & $(.1341)^{* * * *}$ & $(.2363)$ & $(1.841)^{* * *}$ \\
\hline \multirow[t]{2}{*}{ L1. In finc } & - & - & 0.965 & 1.083 & 0.768 \\
\hline & - & - & $(.0125)^{* * * *}$ & $(.0678)^{* * *}$ & $(.1035)^{* * * *}$ \\
\hline \multirow[t]{2}{*}{ L2.ln finc } & - & - & - & -0.077 & 0.028 \\
\hline & - & - & - & $(.0764)$ & $(.1085)$ \\
\hline \multirow[t]{2}{*}{ L1.In $p o p$} & - & - & - & 0.257 & 0.912 \\
\hline & - & - & - & $(.2537)$ & $(.4960)^{*}$ \\
\hline \multirow{2}{*}{$\begin{array}{l}\text { L1.In } \\
\text { water }\end{array}$} & - & - & - & -0.085 & -0.351 \\
\hline & - & - & - & $(.0485)^{*}$ & $(.1398)^{* * * *}$ \\
\hline \multirow[t]{2}{*}{ L1.In ele } & - & - & - & -0.201 & -0.041 \\
\hline & - & - & - & $(.0622)^{* * * *}$ & $(.1318)$ \\
\hline sigma_u & - & 1.968 & - & - & - \\
\hline sigma_e & - & 0.089 & - & - & - \\
\hline rho & - & 0.998 & - & - & - \\
\hline$R$-squared & 0.348 & 0.934 & - & - & - \\
\hline $\begin{array}{l}\text { Sample } \\
\quad \text { size }[N]\end{array}$ & 277 & $\begin{array}{l}277 \\
(n=31)\end{array}$ & $\begin{array}{l}277 \\
(n=31)\end{array}$ & $\begin{array}{l}246 \\
(n=31)\end{array}$ & $246(n=31)$ \\
\hline
\end{tabular}

Arellano-Bond DPD: GMM-type for differenced equation: $\mathrm{L}(2 /$.). In finc L(1/.). In water; standard: LD.In finc D.In pop D.In water D.In ele

DPD-SYS \& Blundell-Bond DPD: GMM-type for level equation: LD.ln finc D.In water; standard: _cons

Arellano-Bond test for H0: no autocorrelation in Fail to Fail to reject first-differenced errors:

Fail to
reject

Note: $N$ is the observations in $n$ provinces of $T$ time periods. Data within the missing years did not participate analysis.

**** Statistical significance in values of $p \leqslant 0.01$.

** For $0.01 \leqslant p \leqslant 0.5$

* For $0.05 \leqslant p \leqslant 0.1$.

tical significant to farmer income. Slightly negative impact of population size is at one present increase to 0.15 percent increase of farmer income. However, exactly as our assumptions, Sargan test for validation of overidentifying restrictions rejected the null hypothesis, and the intercept is statistical significant. Both of that represent some unknown time lags are still needed to be identified.

After taken into consideration of time lags of farmer income and water use as instrumental variables within GMM estimators, the empirical results of Blundell-Bond dynamic panel-data model prove that the level of contemporaneous farmer income has relationship with the previous farmer income and water use. Previous farmer income affects the variation of population, water use, and electricity at the different levels in each province of China. The robust empirical results show that slightly positive impact of water use and electric power consumption are statistical significant to increase contemporaneous farmer income. It seems to match classical consumption theory in that the total consumption brings flourishing. However, it is statistical significant that one percent changes in the first difference time-lag of water use has 0.085 percent of negative impacts on farmer income. It demonstrates water-saving has positive 0.085 percent of impacts on an increase of farmer income in the following year. Moreover, the coefficient of first difference time-lag of farmer income is over one. It further interprets over-consuming water harms farmer income in the following year. Comparing the results of Pool-OLS, the causality of the negative sign of water use on farmer income can be explained by two parts in the results of BlundellBond dynamic panel-data model with GMM estimators: water use has positive relationship with contemporaneous farmer income, and has negative relationship with future farmer income.

To address robust results of this causality, we assume all future regional development depending on the technology improvement at the last level of farmer income. Then, the GMM estimator of just farmer income is set in Blundell-Bond dynamic panel-data model. The analysis results indicate the causality are statistical significance in which water use has positive relationship with contemporaneous farmer income, and has negative relationship with future farmer income. One percent changes in water use will cause 0.19 percent increases in contemporaneous farmer income but 0.35 percent decreases to farmer income in the following year.

\subsection{Regional trend}

Regional diversification can be presented in three sub-models for Eastern, Central, and Western China separately. As Table 6 shows, the first difference of farmer income predetermine to the following year in all three parts of China. Especially, in Western China, the farmer income is highly depending on the previous level of farmer income. Moreover, population has negative relationships with farmer income in China. In Central China, it is statistical significant that one percent of increase in population will induce 0.276 percent of decrease in farmer income. In Western China, one percent of increase in population will induce 0.063 percent of decrease in farmer income. Water use has positive relationship with contemporaneous farmer income in both Central and Western China. In Central China, the average per capita water use was 462 ton which was the highest in three large regions of China in year 2012. The coefficients of water use to farmer income is over 0.124 but it is

Table 6

Empirical analysis results of impact of sparing use of water on farmer income in three large regions of China during years 2004-2012.

\begin{tabular}{|c|c|c|c|c|}
\hline \multirow[t]{2}{*}{ Variables } & Eastern & Central & Western & China in total \\
\hline & \multicolumn{3}{|l|}{ DPD-SYS } & $\begin{array}{l}\text { Blundell-Bond } \\
\text { DPD }\end{array}$ \\
\hline Population & -0.025 & -0.276 & -0.063 & -0.355 \\
\hline$[\ln p o p]$ & $(.0426)$ & $(.0906)^{* * *}$ & $(.0333)^{*}$ & $(.2688)$ \\
\hline Water use & -0.040 & 0.124 & 0.033 & 0.118 \\
\hline [ln water] & $(.0199)^{* *}$ & $(.0570)^{* *}$ & $(.0256)$ & $(.0495)^{* *}$ \\
\hline Electric power & 0.085 & 0.222 & 0.029 & 0.259 \\
\hline [ln ele $]$ & $(.0320)^{* * *}$ & $(.0275)^{* * * *}$ & $(.0230)$ & $(.0710)^{* * * *}$ \\
\hline Intercept & -1.122 & 1.642 & 0.061 & 0.280 \\
\hline [_cons] & $(.5036)^{* * *}$ & $(.6197)^{* * * *}$ & $(.2264)$ & $(.2363)$ \\
\hline \multirow{2}{*}{ L1.ln finc } & 0.973 & 0.840 & 1.027 & 1.083 \\
\hline & $(.0222)^{* * * *}$ & $(.0255)^{* * * *}$ & $(.0204)^{* * * *}$ & $(.0678)^{* * * *}$ \\
\hline \multirow[t]{2}{*}{ L2.ln finc } & - & - & - & -0.077 \\
\hline & - & - & - & $(.0764)$ \\
\hline \multirow[t]{2}{*}{ L1.In pop } & - & - & - & 0.257 \\
\hline & - & - & - & $(.2537)$ \\
\hline \multirow[t]{2}{*}{ L1.In water } & - & - & - & -0.085 \\
\hline & - & - & - & $(.0485)^{*}$ \\
\hline \multirow[t]{2}{*}{ L1.ln ele } & - & - & - & -0.201 \\
\hline & - & - & - & $(.0622)^{* * * *}$ \\
\hline Sample size $[N]$ & 99 & 72 & 106 & 277 \\
\hline Group number $[n]$ & 11 & 8 & 12 & 31 \\
\hline
\end{tabular}

DPD-SYS \& Blundell-Bond DPD:

Instruments for differenced equation: GMM-type: L(2/.).ln finc L(1/.).ln water; standard: D.In pop D.In water D.In ele

Instruments for level equation: GMM-type: LD.In finc D.In water; standard: _cons

Arellano-Bond test Fail to Fail to Fail to Fail to reject for $\mathrm{HO}$ :

reject reject reject

Note: $N$ is the observations in $n$ provinces of $T$ time periods. Data within the missing years did not participate analysis.

Because the availability of sample size is limited, dynamic panel-data model with systematic GMM estimator is used for regional diversification.

Statistical significance in values of $p \leqslant 0.01$.

** For $0.01 \leqslant p \leqslant 0.5$.

For $0.05 \leqslant p \leqslant 0.1$. 
not significant, although it is much higher than that in Western (0.03) and Eastern $(-0.04)$ China. It indicates increase farmer income is much depending on current water consumption because the quotient between water use and population (average water use) in Central China is much higher than that in Western and Eastern China.

Eastern China is more developed than the Central and Western China. The total population in three large regions of China was respectively 558.5 million in Eastern, 425.1 million in Central, and 364.3 million in Western. The average of farmer income in Eastern China was 1870.6 in 2012 USD, which was higher than 1215.2 in 2012 USD in Central China, and 951.8 in 2012 USD in Western China. While per capita water use in Eastern is 390.53 ton in year 2012, which was lower than 462 ton in Central China. With urban expansion has forced land use changes in cultivation in China (Deng et al., 2008), water demand has been increasing for residential living and eco-environmental protection. By empirical results of DPD-SYS model reporting, it is statistical significant that over-consuming water has negative impacts on farmer income in Eastern China where has a higher rate of urbanization than other regions in China. It demonstrates that the potential trade-offs between rural water loss and urban water use. Numerically, when the total amount of water use increases one percent, the contemporaneous farmer income will lose 0.04 percent in Eastern China.

It is statistically significant that electric power have impacts on farmer income in Eastern and Central China. We discuss the autocorrelation in error term due to correlation of water use and electric power consumption. Sargon test gives some hints to further identify autocorrelation between water use and electric power in error term. First time-lag differencing autoregression strokes systematic variance-covariance of autocorrelation. Although the Chi-square results of Sargon test is still not in well satisfaction because of its theoretically inefficient structure, the robust results of Blundell-Bond dynamic panel-data model with GMM estimators of farmer income reported that electric power consumption has inconstant impacts on contemporaneous rural income in the following year. Therefore, water use as a kernel variable is statistical significant. It illustrates one percent of water-saving has positive impacts at $0.085-0.35$ percent on farmer income in the following statistical year.

\section{Conclusion and discussion}

To achieve a target by year 2020, 60 percent of total cultivated land in China will be equipped by irrigation facilities. There will be 434 large irrigation area, and 2157 medium-size irrigation area equipped by water-saving irrigation facilities, all of which will contribute to improve 30 percent of water use efficiency. To test potential changes in farmer income, we design this research.

We estimate impacts of current national sparing use of water on future farmer income. In the section of background information, we point out uneven spatial distributions of water use and farmer income of China, and their ambiguous relationships over time. Population distributed in Eastern China is higher than in Central and Western China sequentially, while water use in Central China is significantly higher than it in Eastern and Western China. To figure out the relationship between average farmer income and national water use, we designed econometric models based on theoretical assumptions in the section of empirical model development.

Empirical results show the statistics of national sparing use of water have negative relationship with contemporaneous farmer income, and slightly benefit average farmer income in the following year. Robust Blundell-Bond DPD model with GMM estimators of both previous farmer income and water use report that one percent of sparing use water will increase 0.085 percent of China's farmer income in the following year. The analysis results of Blundell-Bond dynamic panel-data model only with the GMM estimator of previous farmer income report that a stronger causality of sparing water use has positive relationship with contemporaneous farmer income, and has negative relationship with farmer income in the following year. One percent of water use increase will cause 0.19 percent of contemporaneous farmer income increases but 0.35 percent of farmer income decreases in the following year. Thus, it verifies that statistics of national sparing use of water have slightly benefits to future farmer income at national level in China during years 2004 through 2012.

Particularly, Eastern China has higher population density and higher level of urbanization but lower per capita water use, where one percent of sparing use of water will save 0.04 percent of contemporaneous farmer income. It demonstrates that potential transaction of water use from rural to urban area may harm farmer income attributed to mixed effects of increasing demand of water use for urbanization and increasing population in Eastern China. Numerically, when the total amount of water use increases one percent, the contemporaneous farmer income loses 0.04 percent in Eastern China during years 2004 through 2012.

Sensitivity of water use on farmer income is spatially diversified. Empirical results of DPD-SYS model report that the coefficient of water use to the average farmer income of Central China (0.124) is higher than it in both Eastern (-0.04) and Western (0.03) China. It means that water use to average farmer income changes in Central China is much more sensitive than it in Eastern and Western China. It is caused by that the average amount of per capita water use in Central China (462 ton) is higher than it in Eastern (390.53 ton) and Western (387.73 ton) China. And then, it is reasonable that population has negative relationships with farmer income in China. It is statistical significant that one percent of population increase will induce 0.276 percent of farmer income decrease in Central China, and sequentially higher than in Eastern (0.025) and Western (0.063) China.

Impacts of water allocation on farmer income distribution need to be further detected for regional policy implication of water resource management in different regions of China. Study regional diversification of water use will contribute to understanding the knowledge of a comprehensive system of watershed management, and reinforce the relationships between water allocation and farmer income distribution changes and tradeoffs between rural and urban area. For instance, water-saving for yield increase in Northeastern, water-saving for economic efficiency in Northwestern, study on water-saving for urban expansion in middle of Northern, water-saving for pollution mitigation in Southern China, and water-saving under regional climatic characteristics in Mountain area may further contribute to this issue. Furthermore, to fulfill the strategic plan of "water-saving society" in China, policies reviews and studies of water-saving are further needed. For instance, the cost-benefit analysis of relationships between water quota management and irrigation efficiency, the relevant subsidy of irrigation and monitoring system assessment, market-oriented water allocation and smooth transmission mechanism of water management, and so forth.

\section{Author contributions}

Zhan Wang did modeling works, preformed research, and wrote the paper. Xiangzheng Deng improved and revised paper in all context. Jiancheng Chen contributed to finalize this paper.

\section{Conflicts of Interest}

The authors declare no conflict of interest. 


\section{Acknowledgments}

This research was financially supported by the major research plan of the National Natural Science Funds of China for Distinguished Young Scholar (Grant No. 71225005), the National Natural Science Foundation of China (Grant No. 91325302), and National Key Programme for Developing Basic Science in China (Grant No. 2010СB950900).

\section{Appendix A}

\section{A.1. Derivation of relationships in elasticity $\sigma$}

$\operatorname{finc}(Y)=A(\text { pop })^{\beta_{1}}(\text { water })^{\beta_{2}}(\text { ele })^{\beta_{3}}$

$\ln \operatorname{finc}(Y)=\ln A+\ln (p o p)^{\beta_{1}}+\ln (\text { water })^{\beta_{2}}+\ln (e l e)^{\beta_{3}}$

$\ln \operatorname{finc}(Y)=\alpha+\beta_{1} \ln ($ pop $)+\beta_{2} \ln ($ water $)+\beta_{3} \ln ($ ele $)+e$

Take the FOC,

$\sigma^{\text {pop }}=\frac{\partial \ln \operatorname{finc}(Y)}{\partial \ln \text { pop }}=\beta_{1} ; \sigma^{\text {water }}=\frac{\partial \ln \operatorname{finc}(Y)}{\partial \ln w a t e r}=\beta_{2} ;$

$\sigma^{e l e}=\frac{\partial \ln \operatorname{finc}(Y)}{\partial \ln \text { ele }}=\beta_{3}$.

\section{A.2.}

Table 7

Data description of specified variables in three large regions of China.

\begin{tabular}{|c|c|c|c|c|c|c|}
\hline \multicolumn{2}{|l|}{ Variable } & Mean & Std. Dev. & Min & Max & Observations \\
\hline \multicolumn{7}{|c|}{ Eastern China } \\
\hline \multirow[t]{3}{*}{ ln finc } & Overall & 8.79 & 0.49 & 7.79 & 9.88 & $N=132$ \\
\hline & Between & 0.31 & & 8.34 & 9.29 & $n=11$ \\
\hline & Within & 0.40 & & 8.16 & 9.51 & $T=12$ \\
\hline \multirow[t]{3}{*}{ In pop } & Overall & 8.18 & 0.83 & 6.67 & 9.27 & $N=154$ \\
\hline & Between & 0.86 & & 6.73 & 9.17 & $n=11$ \\
\hline & Within & 0.08 & & 7.96 & 8.43 & $T=14$ \\
\hline \multirow[t]{3}{*}{ ln ele } & Overall & 6.50 & 1.13 & 2.64 & 8.44 & $N=220$ \\
\hline & Between & 0.96 & & 4.08 & 7.44 & $n=11$ \\
\hline & Within & 0.66 & & 4.95 & 7.76 & $T=20$ \\
\hline \multirow[t]{3}{*}{ In water } & Overall & 4.91 & 0.97 & 3.09 & 6.32 & $N=99$ \\
\hline & Between & 1.02 & & 3.13 & 6.30 & $n=11$ \\
\hline & Within & 0.03 & & 4.83 & 4.97 & $T=9$ \\
\hline \multicolumn{7}{|c|}{ Central China } \\
\hline \multirow[t]{3}{*}{$\ln$ finc } & Overall & 8.35 & 0.44 & 7.66 & 9.17 & $N=96$ \\
\hline & Between & 0.07 & & 8.24 & 8.43 & $n=8$ \\
\hline & Within & 0.43 & & 7.66 & 9.09 & $T=12$ \\
\hline \multirow{3}{*}{ In pop } & Overall & 8.50 & 0.38 & 7.89 & 9.18 & $N=112$ \\
\hline & Between & 0.40 & & 7.91 & 9.16 & $n=8$ \\
\hline & Within & 0.02 & & 8.45 & 8.56 & $T=14$ \\
\hline \multirow{3}{*}{ In ele } & Overall & 6.29 & 0.64 & 4.85 & 7.92 & $N=160$ \\
\hline & Between & 0.39 & & 5.74 & 6.95 & $n=8$ \\
\hline & Within & 0.52 & & 5.17 & 7.33 & $T=20$ \\
\hline \multirow[t]{3}{*}{ In water } & Overall & 5.29 & 0.55 & 4.02 & 5.88 & $N=72$ \\
\hline & Between & 0.58 & & 4.11 & 5.79 & $n=8$ \\
\hline & Within & 0.09 & & 5.08 & 5.48 & $T=9$ \\
\hline \multicolumn{7}{|c|}{ Western China } \\
\hline \multirow[t]{3}{*}{ In finc } & Overall & 8.09 & 0.46 & 7.29 & 9.06 & $N=144$ \\
\hline & Between & 0.15 & & 7.88 & 8.33 & $n=12$ \\
\hline & Within & 0.43 & & 7.37 & 8.87 & $T=12$ \\
\hline \multirow[t]{3}{*}{$\ln p o p$} & Overall & 7.66 & 0.97 & 5.55 & 9.03 & $N=168$ \\
\hline & Between & 1.01 & & 5.65 & 9.00 & $n=12$ \\
\hline & Within & 0.04 & & 7.55 & 7.75 & $T=14$ \\
\hline \multirow[t]{3}{*}{ In ele } & Overall & 5.79 & 0.94 & 2.56 & 7.61 & $N=223$ \\
\hline & Between & 0.95 & & 2.92 & 6.65 & $n=12$ \\
\hline & Within & 0.67 & & 4.45 & 7.27 & $T=18$ \\
\hline \multirow[t]{3}{*}{ In water } & Overall & 4.75 & 0.81 & 3.31 & 6.38 & $N=108$ \\
\hline & Between & 0.84 & & 3.42 & 6.27 & $n=12$ \\
\hline & Within & 0.05 & & 4.59 & 4.88 & $T=9$ \\
\hline
\end{tabular}

\section{References}

Rosegrant, M.W., Cai, X., Cline, S.A., 2002. World Water and Food to 2025: Dealing with Scarcity. Intl Food Policy Res Inst.

Singh, R.B., 1998. Land use/cover changes, extreme events and ecohydrological responses in the Himalayan region. Hydrol. Process. 12 (13-14), 2043-2055.

World Bank Group (Ed.), 2012. World Development Indicators 2012. World Bank Publications.

Jiang, L., Wu, F., Liu, Y., Deng, X., 2014. Modeling the impacts of urbanization and industrial transformation on water resources in China: an integrated hydroeconomic CGE analysis. Sustainability 6 (11), 7586-7600.

Deng, X., Zhao, C., 2014. Identification of water scarcity and providing solutions for adapting to climate changes in the Heihe River Basin of China. Adv. Meterol. 2014. http://dx.doi.org/10.1155/2014/279173 [Article ID 292768].

Deng, X., Zhang, F., Wang, Z., Li, X., Zhang, T., 2014. An extended input output table compiled for analyzing water demand and consumption at county level in China. Sustainability 6 (6), 3301-3320.

Kelly, P., 2014. What to do when we run out of water. Nat. Clim. Change 4 (5), 314 316.

Wang, H., Liu, C., Zhang, L., 2002. Water-saving agriculture in China: an overview. Adv. Agron. 75, 135-171.

Blanke, A., Rozelle, S., Lohmar, B., Wang, J., Huang, J., 2007. Water saving technology and saving water in China. Agric. Water Manage. 87 (2), 139-150.

Gilg, A., Barr, S., 2006. Behavioural attitudes towards water saving? Evidence from a study of environmental actions. Ecol. Econ. 57 (3), 400-414.

Wang, Z., Deng, X., Li, X., Zhou, Q., Yan, H., 2015. Impact analysis of government investment on water projects in the arid Gansu Province of China. Phys. Chem. Earth, Parts A/B/C 79, 54-66.

Perry, C.J., Seckler, D., Rock, M.T., Seckler, D.W., 1997. Water as An Economic Good: A Solution or a Problem?, vol 14. IWMI.

Samuelson, P.A., 1948. Consumption theory in terms of revealed preference. Economica, 243-253.

Kelman, M., 1978. Consumption theory, production theory, and ideology in the Coase theorem. S. Cal. L. Rev. 52, 669.

Wade, R., 1990. Governing the Market: Economic Theory and the Role of Government in East Asian Industrialization. Pfinceton University Press.

Solow, R.M., 1974. The economics of resources or the resources of economics. Am. Econ. Rev. 64 (2), 1-14.

Brown, L.R., Halweil, B., 1998. China's water shortage could shake world food security. World Watch 11 (4), 10-21.

Cabraal, R.A., Barnes, D.F., Agarwal, S.G., 2005. Productive uses of energy for rural development. Annu. Rev. Environ. Resour. 30, 117-144.

Maddala, G.S., Wu, S., 1999. A comparative study of unit root tests with panel data and a new simple test. Oxford Bull. Econ. Stat. 61 (S1), 631-652.

Arellano, M., Bond, S., 1991. Some tests of specification for panel data: Monte Carlo evidence and an application to employment equations. Rev. Econ. Stud. 58 (2), 277-297.

Bowsher, C.G., 2002. On testing overidentifying restrictions in dynamic panel data models. Econ. Lett. 77 (2), 211-220.

Blundell, R., Bond, S., 1998. Initial conditions and moment restrictions in dynamic panel data models. J. Econom. 87 (1), 115-143.

Blundell, R., Bond, S., 2000. GMM estimation with persistent panel data: an application to production functions. Econom. Rev. 19 (3), 321-340.

Deng, X., Huang, J., Rozelle, S., Uchida, E., 2008. Growth, population and industrialization, and urban land expansion of China. J. Urban Econ. 63 (1) 96-115. 